\title{
Easy Bruising
}

National Cancer Institute

\section{Source}

National Cancer Institute. Easy Bruising. NCI Thesaurus. Code C119027.

Appearance of skin bruises following perceived minimal contact or injury. 